\title{
Research on the Increasing Law and Authors Distribution of Medical Records Management Literature in China
}

\author{
Zhou Ting \\ School of Information Engineering \\ Hubei University of Chinese Medicine \\ Wuhan, China
}

\author{
Hu Yue \\ School of Information Engineering \\ Hubei University of Chinese Medicine \\ Wuhan, China
}

\author{
Cai Lijun \\ School of Information Engineering \\ Hubei University of Chinese Medicine \\ Wuhan, China
}

\begin{abstract}
Based on literature growth model and Lotka's law in informetrics, this thesis targets at medical records management literature from China National Knowledge Infrastructure (CNKI), researches on their growth from 1956 to 2015 to find a two-phase linear growth model. Meanwhile, maturity of medical records management is concluded from analys is of relevant authors. Generally, China's medical records management is heading to further development but still remain in earlier stage, in which author group expands and prefer collaboration in paper presentation, while researches are not mature.
\end{abstract}

Keywords-medical records management; literature growth pattern; Lotka's law; author analysis

\section{INTRODUCTION}

With further development of medical system reform, growth on population with medical and commercial insurance and enhanced legal consciousness, medical records, the source and evidence for cases, are gradually brought to the forefront. Office of medical records management serves as a potential window due to increasing medical record referring and printing [1]. Researchers are key elements for promoting science development. By researching on their quantity and working pattern, people can notice influential authors, rate scientific productivity, clear researches structure and distribution, finally predict authors' growth as well as scale and trend of science development ${ }^{[2]}$. Analyzing on medical records management literature, relevant authors' quantity and research teams' current development, this thesis will present China's current situation in medical records management and provide reference advices for its healthy and sustainable development.

\section{Data Resource And Methodology}

\section{A. Data Resource}

Based on China National Knowledge Infrastructure (CNKI), the research team acquired 8,742 satisfactory literatures over 60 years (1956-2015) after filtration.

\section{B. Methodology}

The research team analyzes growth pattern of medical records management literature with literature growth model while requency and distribution pattern of qualified literature authers is measured with Lotka's law in informetrics.

\section{ANALYSIS ON LITERATURE GROWTH PATTERN}

\section{A. Basic situation of document growth}

As a main record carrier of medical cases, medical records management literature's quantity growth is a significant indicator to directly reflect medical cases' development and trend. TABLE I illustrates anual number, year-on-year growth and total quantity of medical records management literature from 1956 to 2015.

TABLE I. MEDICAL RECORDS MANAGEMENT LitERATURE FROM 1956 TO 2015

\begin{tabular}{|cccc|cccc|}
\hline Year Number & $\begin{array}{c}\text { Year-on-year } \\
\text { Growth }\end{array}$ & Total & Year Number & $\begin{array}{c}\text { Year-on-year } \\
\text { Growth }\end{array}$ & Total \\
\hline 1956 & 1 & 0 & 1 & 1997 & 293 & 166 & 1073 \\
1965 & 2 & 2 & 3 & 1998 & 138 & -155 & 1211 \\
1979 & 1 & 1 & 4 & 1999 & 122 & 16 & 1333 \\
1981 & 5 & 4 & 9 & 2000 & 184 & 62 & 1517 \\
1982 & 5 & 0 & 14 & 2001 & 434 & 250 & 1951 \\
1983 & 11 & 6 & 25 & 2002 & 451 & 17 & 2402 \\
1984 & 1 & -10 & 26 & 2003 & 557 & 106 & 2959 \\
1985 & 4 & 3 & 30 & 2004 & 573 & 16 & 3532 \\
\hline
\end{tabular}




\begin{tabular}{|cccc|cccc|}
\hline \multicolumn{7}{|c|}{ Cont. to TABLE I } \\
\hline 1986 & 4 & 0 & 34 & 2005 & 459 & -114 & 3991 \\
1987 & 6 & 2 & 40 & 2006 & 638 & 179 & 4629 \\
1988 & 9 & 3 & 49 & 2007 & 478 & -160 & 5107 \\
1989 & 8 & -1 & 57 & 2008 & 448 & -30 & 5555 \\
1990 & 10 & 2 & 67 & 2009 & 479 & 31 & 6034 \\
1991 & 8 & -2 & 75 & 2010 & 475 & 4 & 6509 \\
1992 & 19 & 11 & 94 & 2011 & 497 & 22 & 7006 \\
1993 & 20 & 1 & 114 & 2012 & 437 & -60 & 7443 \\
1994 & 75 & 55 & 189 & 2013 & 445 & 8 & 7888 \\
1995 & 464 & 389 & 653 & 2014 & 450 & 5 & 8338 \\
1996 & 127 & -337 & 780 & 2015 & 404 & -46 & 8742 \\
\hline
\end{tabular}

The literatures growth indicates that its quantity varies with time, which reveals characteristics and patterns of subject development. TABLE I shows a slow growth of literatures before 1993 with an annual average growth of 3 and reached a peak of 20. Since 1994, increasing attention brought literatures an annual growth of 392.2 and the fastest growth came in 2016, with 638 literatures in one year.

\section{B. Literature Growth Model}

Based on the relation of time and total literature quantity, the research team can draw curve of scatter plots as Fig.1.

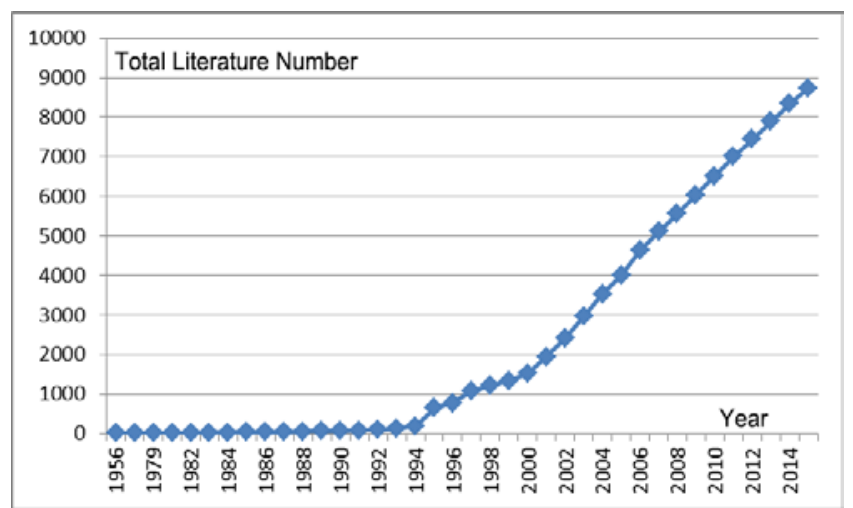

Fig. 1. Quantity Curve of Medical Records Management Literature 19562010

Fig. 1 shows literature quantity before 1993 is too small so the research team conducts regression analysis on data from 1994 to 2015. After linear and exponential fitting in SPSS, the team acquires model parameters and curve in Fig. $2\left(\mathrm{R}^{2}=0.983\right.$ in the linear, $\mathrm{R}^{2}=0.899$ in the exponential). The curve shows higher relevancy degree in linear fitting, which means growth trend between 1994 and 2015 is more approximate to linear growth model.

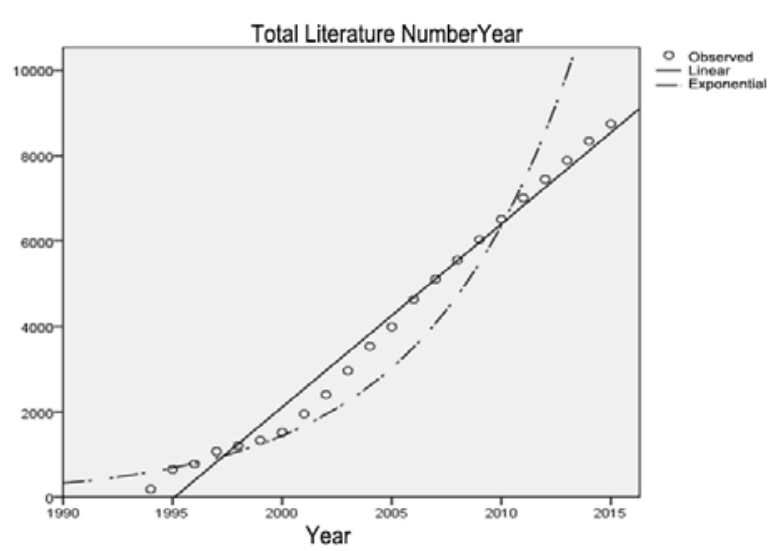

Fig. 2. Growth Fitting Curve of Medical Records Management Literature

\section{Analysis on Development Stages of Medical Records}

China's medical records management started in 1921, the same time with Peking Union Medical College Hospital's establishment. The development medical records management can be divided into two phases according to analysis above ${ }^{[3]}$.

The first stage is from 1921 to 1993, a period with low literature publication level of medical records management, and the only one article- "Improve Medical Records Quality, Manage Relevant Work Well” was published in 1956.

The second stage is from 1994 to recent days. In 1994, the ministry of health released Detailed Rules for Administration of Medical Institutions, in which stipulate clinic records being on file for at least 15 years while hospitalization record for at least 30 years. Peking University Health Science Center started undergraduate course of medical information management in 2002, while the ministry of health and state administration of traditional Chinese medicine published Chinese Medical Record in the same year. In this process, medical records have aroused attention from the public and government so that rules and laws were introduced in succession, leading to a gradual increase of medical record management literatures.

\section{Analysis on Growth Pattern of Literatures}

\section{A. Annual Number of authors}

According to the statistics, there are 9410 authors of medical records management literature in total with 17691 person times. Due to slow growth from 1956 to 1993, this period is regard as one statistical year. Author quantity in different years is showed below in TABLE I. Personal number of published articles can be worked out with the total number of articles and authors ${ }^{[4]}$. It is demonstrated that average number is less than 1 article per person. 
TABLE II. AUTHOR QUANTITY FROM 1956 TO 2015

\begin{tabular}{|c|c|c|c|c|}
\hline Year & Number of Author & Person Time & Total Publication & Average Publication \\
\hline $1956-1993$ & 195 & 207 & 114 & 0.58 \\
\hline $1994-1997$ & 1333 & 1710 & 959 & 0.72 \\
\hline $1998-2001$ & 1236 & 1700 & 878 & 0.71 \\
\hline $2002-2005$ & 2334 & 3742 & 2040 & 0.87 \\
\hline $2006-2009$ & 2666 & 4183 & 2043 & 0.77 \\
\hline $2010-2013$ & 2828 & 4071 & 1854 & 0.65 \\
\hline $2014-2015$ & 1601 & 2078 & 854 & 0.53 \\
\hline
\end{tabular}

\section{B. Annual Analysis on Coauthor}

Degree and rate of cooperation varies from subject characteristics when high value means stronger cooperation trend with obvious subject cross. Formula: Cooperation Degree $=$ Author Number/ Article Number (in certain periodical period); Cooperation Rate= Cooperation Article Number/ Total Article Number $* 100 \%{ }^{[5]}$.

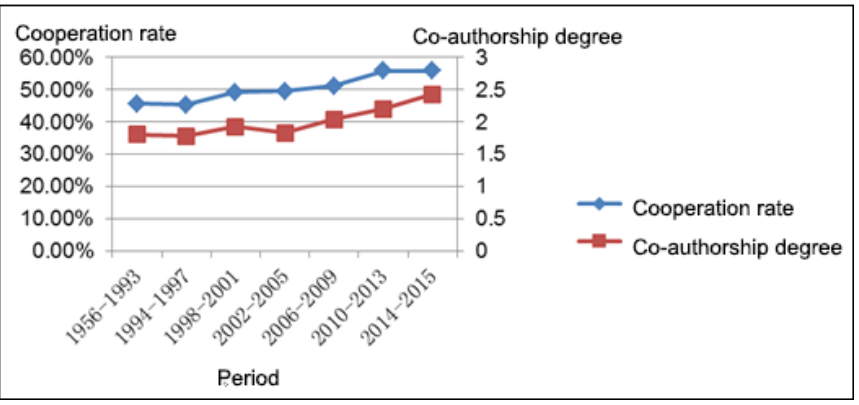

Fig. 3. Annual Cooperation Degree Cooperation Rate

Fig.3 illustrates an increasing cooperation degree that at least 2 persons write in collaboration with each other for one article annually, with the highest record of 2.43 persons from 2014 to 2015, indicating growing cooperation in medical records research and more communication between researchers.

\section{Lotka Fitting Analysis}

Lotka's Law describes the distribution of authors in informetrics. The generalized Lotka's law reveals the relationship between author ratio and the number of documents, and describes the frequency distribution law of scientific productivity. Its mathematical expression is: $y(x)=C / x^{n}(1.2<n<3.8)$ in which $\mathrm{y}(\mathrm{x})$ means number of authors who writing $x$ pieces of articles ${ }^{[6]}$. The research team chooses the first author in each group to figure out whether author distribution in medical record management lectures fit generalized law of Lotca and the result is shown in TABLE III.
TABLE III. AUthors' PUBLICATION FREQUENCY

\begin{tabular}{|cc|cc|cc|}
\hline $\begin{array}{c}\text { Article } \\
\text { Number x }\end{array}$ & $\begin{array}{c}\text { Author } \\
\text { Number } \\
\mathrm{y}(\mathrm{x})\end{array}$ & $\begin{array}{c}\text { Article } \\
\text { Number } \\
\mathrm{x}\end{array}$ & $\begin{array}{c}\text { Author } \\
\text { Number } \\
\mathrm{y}(\mathrm{x})\end{array}$ & $\begin{array}{c}\text { Article } \\
\text { Number } \\
\mathrm{x}\end{array}$ & $\begin{array}{c}\text { Author } \\
\text { Number } \\
\mathrm{y}(\mathrm{x})\end{array}$ \\
\hline 1 & 3313 & 8 & 27 & 15 & 3 \\
2 & 823 & 9 & 14 & 16 & 0 \\
3 & 342 & 10 & 12 & 17 & 2 \\
4 & 169 & 11 & 12 & 18 & 1 \\
5 & 108 & 12 & 8 & 19 & 1 \\
6 & 53 & 13 & 3 & 28 & 1 \\
7 & 40 & 14 & 5 & & \\
\hline
\end{tabular}

According to data above, author group is considerable in this field, which is not fit for K-S examination ${ }^{[9]}$. Therefore, non-regression analysis is conducted to directly estimate parameters $\mathrm{c}$ and $\mathrm{n}$ in Lotka's Law.

On the basis of formula $c=1 / \sum_{x=1}^{\infty} \frac{1}{x^{n}}$, c can be worked out to match $\mathrm{n}$ in planning precision as TABLE IV shows ${ }^{[7]}$.

TABLE IV. MATCHING BETWEEN C AND N

\begin{tabular}{|c|c|c|c|c|c|c|c|c|c|}
\hline $\mathrm{n}$ & $\ldots$ & 2.124 & 2.125 & 2.126 & $\ldots$ & 2.288 & 2.289 & 2.290 & $\ldots$ \\
\hline $\mathrm{c}$ & $\ldots$ & 0.6484 & 0.6487 & 0.6490 & $\ldots$ & 0.6950 & 0.6952 & 0.6955 & $\ldots$ \\
\hline
\end{tabular}

Base on TABLE III (processing $1 \leq x \leq 15$ ), frequency of one article by authors is $G=y(1) / \sum_{1}^{15} y(x)=0.6717$. At the significant level of 0.01 , K-S examination allows max number $D_{\max }=1.63 / \sqrt{\sum_{1}^{15} y(x)}=0.0232$. In the G-centered range with a radius of $D_{\max }, c \in\left(G-D_{\max }, G+D_{\max }\right)^{[7]}$, c ranges from 0.6485 to 0.6949 , matching with $\mathrm{n}$ from 2.124 to 2.288 according to TABLE IV.

Starting from $n=2.13, c=0.6502$, the research team calculated deviation between theoretical and fact cumulative frequency with $\mathrm{n}$ increasing in a certain length. $S_{j}$ stands for cumulative frequency of writing 1 to $\mathrm{j}$ pieces articles with parameters $\left(n_{i}, c_{i}\right)$ [7]. 
TABLE V. MAXIMAL DEVIATION BETWEEN THEORETICAL AND FACT CUMULATIVE FREQUENCY

\begin{tabular}{|c|c|c|c|}
\hline No. & $\mathrm{n}$ & C & $\operatorname{Max}\left|S_{j}(n, c)-S_{j}\right|$ \\
\hline 1 & 2.130 & 0.6502 & 0.04770537 \\
\hline 2 & 2.140 & 0.6533 & 0.04586255 \\
\hline 3 & 2.150 & 0.6563 & 0.04415725 \\
\hline 4 & 2.160 & 0.6593 & 0.04244847 \\
\hline 5 & 2.170 & 0.6622 & 0.04087559 \\
\hline 6 & 2.180 & 0.6651 & 0.03929838 \\
\hline 7 & 2.190 & 0.6680 & 0.03771682 \\
\hline 8 & 2.200 & 0.6709 & 0.03613085 \\
\hline 9 & 2.210 & 0.6737 & 0.03467841 \\
\hline 10 & 2.220 & 0.6766 & 0.03308318 \\
\hline 11 & 2.230 & 0.6793 & 0.03175796 \\
\hline 12 & 2.240 & 0.6821 & 0.03028991 \\
\hline 13 & 2.250 & 0.6848 & 0.02895318 \\
\hline 14 & 2.260 & 0.6875 & 0.02761050 \\
\hline 15 & 2.270 & 0.6902 & 0.02626186 \\
\hline 16 & 2.280 & 0.6929 & 0.02490727 \\
\hline 17 & 2.281 & 0.6931 & 0.02486340 \\
\hline 18 & 2.282 & 0.6934 & 0.02468983 \\
\hline 19 & 2.283 & 0.6937 & 0.02451328 \\
\hline 20 & 2.284 & 0.6939 & 0.02447210 \\
\hline 21 & 2.285 & 0.6942 & 0.02429543 \\
\hline 22 & 2.286 & 0.6945 & 0.02411872 \\
\hline 23 & 2.287 & 0.6947 & 0.02407729 \\
\hline 24 & 2.2871 & 0.6948 & 0.02396489 \\
\hline 25 & 2.2872 & 0.6948 & 0.02398781 \\
\hline 26 & 2.2873 & 0.6948 & 0.02401072 \\
\hline 27 & 2.2874 & 0.6948 & 0.02403363 \\
\hline 28 & 2.2875 & 0.6949 & 0.023921238 \\
\hline
\end{tabular}

When $\mathrm{n}=2.2875$, $\mathrm{c}=0.6949$,

$$
\begin{aligned}
& (n, c)=\left\{(n, c) \mid \min \left[\max \left(\left|S_{j}\left(n_{i}, c_{i}\right)-S_{j}\right|\right)\right]\right\} \\
& \quad \text { sets up }{ }^{[8]} \cdot C=y(x) * c=3427.2468 \\
& \text { so that } y(x)=3427.2468 / x^{2.2875}
\end{aligned}
$$

In Lotka's Law, constant c is related to the field maturity. Large c means lower degree of maturity. With the increase of maturity, c will gradually reach the constant in standard Lotka's Law ${ }^{[8]}$. The $c=0.6949$ got above is a little bit greater than the standard c=0.6079, which means medical record management is still not mature. Moreover, power exponent $\mathrm{n}$ presents dispersion degree of authors' frequency. When $n=2.2875$, greater than standard $n=2$, it indicates a strong dispersion trend in this field.

\section{CONCLUSION}

The growth pattern of scientific literatures reveals the process of slow development in the early stage, then acceleration, deceleration in the late stage and finally saturation. Above all, medical record management remains in its early stage, heading for next phase.

It is meaningful for the subject development to trace researchers' work when intensive knowledge discovery, theory research and industrial application are further advancing. To sum up, author group in medical record management is go from strength to strength and tend to cooperate in article publication. However, this filed remains in an immature stage according to Lotka's Law.

\section{REFERENCES}

[1] Lei Guidian. A New Model of Medical Record Management in Harmonious Society [J]. Chinese Medical Record, 2006, 7(6):8-10

[2] Qiu Junping, Yang Siluo, Zhou Chunlei. Analyses of the Authors in the Articles of Information Science in China in the Past 30 Years[J].Journal of The China Society For Scientific and Technical Information, 2009, 28(4):626-633

[3] Feng Yi, Li Jikun, Li Xiaomei. The Development Status and Future of Medical Record Management in China[J].Chinese Journal of Hospital Administration, 2008, 24:74-75

[4] Qiu Junping, Lou Wen. Analyses of the Authors in the Articles of Index in China in the Past 20 Years[J].Information Science, 2013, 31(3):72-75

[5] Wang Wei. Information Metrology and Its Medical Application [M] Beijing: People's Medical Publishing House, 2014:110

[6] Qiu Junping. Informetrics [M]. Wuhan:Wuhan University Press, 2007

[7] Zhang Xian'ao. Direct Estimation of Lotka's Law Parameters n and c for Non-regressive Analysis [J] Library and Information Service, 1991, (6):27-33

[8] Sun Zhenjia. Maturity Analysis of "Science and Technology Information Resources” Research Based on Lotka's Law, 2012, 35(9): 82-85

[9] Zhang Haiyan. Bibliometrics-based Lotka's law: A review[J].Chinese Journal of Medical Library and Information Science, 2013, 22(8):18-21

[10] Zhao Shanming, Wu Hanrong, Neng Changhua. The Curves of Document Increase in the Field of Psychotherapy, a Comparison between Chinese and International Documents[J].Chinese Mental Health Journal, 2003, 17(11):794-795 